\title{
EDITORIAL
}

\section{Guidelines for the diagnoses and treatment of adult lower respiratory tract infections: a true "European cooperative effort"}

\author{
M.I. Restrepo**, and A. Anzueto ${ }^{\#}$
}

T hroughout history, the diagnosis and treatment of lower respiratory tract infections (LRTIs) has been a "European cooperative effort". Since the experiments of R. Koch, many scientists have identified the role of infectious agents, including bacteria, in these conditions and different alternative treatments required to combat them. In 1888, E. de Freudenreich isolated bacterial secretions and noted their inherent, antibacterial properties. Later, in 1896, E. Duchesne noted that certain penicillium moulds killed bacteria, findings that were later confirmed by A. Fleming. We all know the history that follows ..., but today we have new challenges to overcome.

In the current issue of the European Respiratory Journal, WOODHEAD et al. [1] present the guidelines of the European Respiratory Society (ERS) and European Society of Clinical Microbiology and Infectious Diseases (ESCMID), based on a systematical appraisal of the existing literature for diagnosis and management of adult LRTIs. These guidelines provide recommendations for the diagnosis and treatment of the three most common LRTIs: community-acquired pneumonia (CAP), acute exacerbations of chronic obstructive pulmonary disease (COPD; AECB) and exacerbations of bronchiectasis.

CAP remains a common, serious and potentially lifethreatening disease, particularly in elderly patients and those subjects associated with risk factors for resistant pathogens [2, 3]. Multiple sets of CAP guidelines have been published in order to address the continued changes in the complexity of this disease, including those in prior versions of the ERS guidelines [4-9]. These guidelines help clinicians to stratify patients by risk factors, and provide a range of diagnostic and treatment options in the community, hospital wards or intensive care units. The implementation of CAP guidelines have resulted in a significant reduction in morbidity and mortality [10-15]; safely identified patients that can be treated as outpatients, resulting in decreased hospitalisations rates [16]; decreased the length of time a patient needs to stay in

\footnotetext{
*VERDICT, Audie L Murphy VA Hospital at South Texas Veterans Health Care System and \# University of Texas, Health Science Center at San Antonio, Divisions of Pulmonary and Critical Care Medicine, San Antonio, TX, USA.

CORRESPONDENCE: A. Anzueto, University of Texas, Health Science Center at San Antonio, Division of Pulmonary and Critical Care Medicine, South Texas Veterans Health Care System Audie L Murphy division at San Antonio, 7400 Merton Minter Boulevard, San Antonio 78284, Texas, USA. Fax: 1 2105676677. E-mail: anzueto@uthscsa.edu
}

hospital [17, 18]; and led to the significant improvement in the processes of care of this disease $[19,20]$. The CAP guidelines have also outlined the lack of clinical evidence in certain areas. These observations stimulated ongoing clinical research in order to further clarify the interaction between pathogens, their resistance patterns, antibiotic treatment and other costeffective therapies.

The ERS/ESCMID CAP guidelines are centred on the following main questions: how do I diagnose or identify CAP?; how should I treat my patient with CAP?; and how should I prevent CAP? The guidelines emphasise the necessity that clinicians identify other conditions frequently confused with LRTI, such as aspiration pneumonia, pulmonary embolism and even chronic airway disease. In order to differentiate pneumonia from other LRTIs, the patient should have the following clinical findings: acute onset of cough, dyspnoea, new focal chest signs, tachypnea, and fever $>4$ days, with the presence of an infiltrate on a chest radiograph. Patients with a LRTI are frequently seen in the primary care setting. Thus, the guidelines do not recommend outpatient testing for aetiological causes of LRTI. The recommendations for the early use of antimicrobial therapy, is based on the severity of illness; frequency of specific pathogens; local patterns of microbial resistance; and safety profile. The guidelines emphasise that since there is a strong probability of a viral aetiology, antibiotics should be withheld to reduce cost and simultaneously minimise the emergence of antibiotic-resistant bacterial strains in the community. However, the guidelines did not take into consideration the local formulary restriction that healthcare providers may encounter. There is also no mention of resistant patterns in areas of Eastern Europe or other regions that may influence bacterial resistance in the rest of the continent. Furthermore, these guidelines have identified significant weaknesses in the information available to make decisions related to hospitalisation, the switch from parenteral to oral therapy and the length of stay in hospital. All these parameters are influenced by local healthcare systems and generalised recommendations may be impossible to implement.

We applaud the committee's decision not to limit these guidelines to CAP but also to include other LRTIs. In particular, the inclusion of AECB is a milestone for the recognition of this disease. Chronic bronchitis is complicated by recurrent episodes of acute exacerbations, which contribute to significant impartment in patient's quality of life, and 
overall morbidity and mortality [21, 22]. This is a clinical condition that is associated with an unacceptable rate of relapse and clinical failures that contribute to hospitalisations and mortality $[23,24]$. Although we believe that it is a mistake to separate the use of antibiotics from other therapeutic measures, such as corticosteroids and bronchodilators, this topic was recently reviewed by the ERS and American Thoracic Society [25] and was beyond the "infectious approach" of this publication.

These ERS/ESCMID guidelines address significant controversial points, mainly the role of infection and the usage of antimicrobials in AECB. AECB is known to be precipitated by both noninfectious and infectious conditions [26]. It is important that the clinician recognises that noninfectious causes of AECB may be due to a broad, differential diagnosis, including congestive heart failure, pulmonary embolism, seasonal allergies, etc. Infectious processes have focused on bacteria, primarily nontypable Haemophilus influenzae, Moraxella catharrhalis and Streptococcus pneumoniae, but we have to recognise that other pathogens, such as viruses [27] and Chlamydophila pneumoniae, can also be involved [28]. The clinical decision becomes more complicated when many of the pathogens are present in the patient's lower airway during stable conditions, and multiple pathogens may be present at the same time during an acute exacerbation of COPD. We currently lack the appropriate diagnostic tools to make this differentiation. Thus, the guidelines focus on treatment recommendations based on the "place of care" (patients not requiring hospitalisation or admittance to hospital) and the identification of clinical characteristics that are related to bacterial pathogens, mainly Pseudomonas aeruginosa.

Despite all the benefits of clinical guidelines outlined in this Editorial, practitioners have not fully used or embraced LRTI guidelines. Guidelines were never meant to be followed in $100 \%$ of cases; clinicians should rely simply on sound clinical judgment when dealing with specific cases. For example, other factors such as the patient's ability to care for themself have to be considered. It is possible that clinicians do not use treatment guidelines because of "guideline fatigue". Traditionally, these publications are long documents, which need to be studied indepth in order to extract critical information that could be useful in patient care. These ERS/ESCMID guidelines are presented in a question and answer format, with a comprehensive summary and pertinent literature references to support each statement. This format is easy to search, read and remember. Therefore, the apparent gap between evidencebased medicine and clinical-practice in LRTIs has been significantly closed by these guidelines.

The LRTI ERS/ESCMID guidelines are the net result of a rigorous, evidence-based review process; in this case the committee members reviewed over 4,000 publications! National and international effort will be necessary to bring clinical science into clinical practice. In addition the impact of these guidelines will depend on the enthusiasm with which they are disseminated, their incorporation into clinical practice and, more importantly the clinician access to the information at the bedside. Thus, it is imperative to have pocket versions and/or personal handheld computerised, electronic versions.
The ERS/ESCMID guideline development has to be a dynamic process, in which the mechanisms for frequent updates have to be in place. The ERS/ESCMID and their respective journals must take advantage of their electronic capabilities in order to facilitate this process. Furthermore, it is necessary to expedite the process of literature review. For example, in this publication, most of the latest references are from 2003, yet there is a significant body of new information available related to rapidly emerging changes in susceptibility patterns for specific pathogens, changes in local susceptibility profiles, and availability of new antibiotics that are not included in these guidelines. These guidelines, though, are one more important step in the fight against LRTIs.

To conclude, these guidelines summarise the current knowledge of these diseases, but in order to understand the major challenge that we have ahead, let us remember what F. MartiIbanez, a Spanish physician and historian predicted in 1955: "Antibiotic therapy if indiscriminately used, may turn out to be a medicinal food that temporarily cleans and heals, but ultimately destroys life itself."

\section{REFERENCES}

1 Woodhead M, Blasi F, Ewig S, et al. Guidelines for the management of adult lower respiratory tract infections. Eur Respir J 2005; 26: 1138-1180.

2 Centers for Disease Control and Prevention (CDC). Update: influenza activity-United States and worldwide, 1999-2000 season, and composition of the 2000-01 influenza vaccine. MMWR 2000; 49: 375-381.

3 National Center for Health Statistics CDC. Advance report of final mortality statistics 1992. Hyattsville, US Department of Health and Human Services Public Health Service, 1994.

4 ERS Task Force Report. Guidelines for management of adult community-acquired lower respiratory tract infections. European Respiratory Society. Eur Respir J 1998; 11: 986-991.

5 Bartlett JG, Dowell SF, Mandell LA, File TM Jr, Musher DM, Fine MJ. Practice guidelines for the management of community-acquired pneumonia in adults. Infectious Diseases Society of America. Clin Infect Dis 2000; 31: 347-382.

6 Heffelfinger JD, Dowell SF, Jorgensen $\mathrm{JH}$, et al. Management of community-acquired pneumonia in the era of pneumococcal resistance: a report from the DrugResistant Streptococcus pneumoniae Therapeutic Working Group. Arch Intern Med 2000; 160: 1399-1408.

7 Mandell LA, Bartlett JG, Dowell SF, File TM Jr, Musher DM, Whitney C. Update of practice guidelines for the management of community-acquired pneumonia in immunocompetent adults. Clin Infect Dis 2003; 37: 1405-1433.

8 Mandell LA, Marrie TJ, Grossman RF, Chow AW, Hyland RH. Canadian guidelines for the initial management of community-acquired pneumonia: an evidencebased update by the Canadian Infectious Diseases Society and the Canadian Thoracic Society. The Canadian Community-Acquired Pneumonia Working Group. Clin Infect Dis 2000; 31: 383-421. 
9 Niederman MS, Mandell LA, Anzueto A, et al. Guidelines for the management of adults with community-acquired pneumonia. Diagnosis, assessment of severity, antimicrobial therapy, and prevention. Am J Respir Crit Care Med 2001; 163: 1730-1754.

10 Dean NC, Silver MP, Bateman KA, James B, Hadlock CJ, Hale D. Decreased mortality after implementation of a treatment guideline for community-acquired pneumonia. Am J Med 2001; 110: 451-457.

11 Weingarten SR, Riedinger MS, Hobson $\mathrm{P}$, et al. Evaluation of a pneumonia practice guideline in an interventional trial. Am J Respir Crit Care Med 1996; 153: 1110-1115.

12 Capelastegui A, Espana PP, Quintana JM, et al. Improvement of process-of-care and outcomes after implementing a guideline for the management of communityacquired pneumonia: a controlled before-and-after design study. Clin Infect Dis 2004; 39: 955-963.

13 Houck PM, MacLehose RF, Niederman MS, Lowery JK. Empiric antibiotic therapy and mortality among medicare pneumonia inpatients in 10 western states: 1993, 1995, and 1997. Chest 2001; 119: 1420-1426.

14 Mortensen EM, Restrepo M, Anzueto A, Pugh J. Effects of guideline-concordant antimicrobial therapy on mortality among patients with community-acquired pneumonia. Am J Med 2004; 117: 726-731.

15 Suchyta MR, Dean NC, Narus S, Hadlock CJ. Effects of a practice guideline for community-acquired pneumonia in an outpatient setting. Am J Med 2001; 110: 306-309.

16 Marrie TJ, Lau CY, Wheeler SL, Wong CJ, Vandervoort MK, Feagan BG. A controlled trial of a critical pathway for treatment of community-acquired pneumonia. CAPITAL Study Investigators. Community-Acquired Pneumonia Intervention Trial Assessing Levofloxacin. JAMA 2000; 283: 749-755.

17 Fine MJ, Stone RA, Lave JR, et al. Implementation of an evidence-based guideline to reduce duration of intravenous antibiotic therapy and length of stay for patients hospitalized with community-acquired pneumonia: a randomized controlled trial. Am J Med 2003; 115: 343-351.

18 Meehan TP, Weingarten SR, Holmboe ES, et al. A statewide initiative to improve the care of hospitalized pneumonia patients: The Connecticut Pneumonia Pathway Project. Am J Med 2001; 111: 203-210.

19 Benenson R, Magalski A, Cavanaugh S, Williams E. Effects of a pneumonia clinical pathway on time to antibiotic treatment, length of stay, and mortality. Acad Emerg Med 1999; 6: 1243-1248.

20 Chu LA, Bratzler DW, Lewis RJ, et al. Improving the quality of care for patients with pneumonia in very small hospitals. Arch Intern Med 2003; 163: 326-332.

21 Connors AF Jr, Dawson NV, Thomas C, et al. Outcomes following acute exacerbation of severe chronic obstructive lung disease. The SUPPORT investigators (Study to Understand Prognoses and Preferences for Outcomes and Risks of Treatments). Am J Respir Crit Care Med 1996; 154: 959-967.

22 Seemungal TA, Donaldson GC, Paul EA, Bestall JC, Jeffries DJ, Wedzicha JA. Effect of exacerbation on quality of life in patients with chronic obstructive pulmonary disease. Am J Respir Crit Care Med 1998; 157: 1418-1422.

23 Adams SG, Melo J, Luther M, Anzueto A. Antibiotics are associated with lower relapse rates in outpatients with acute exacerbations of COPD. Chest 2000; 117: 1345-1352.

24 Miravitlles M. Exacerbations of chronic obstructive pulmonary disease: when are bacteria important? Eur Respir J 2002; 20: Suppl. 36, 9S-19S.

25 Celli BR, MacNee W, Force AET. Standards for the diagnosis and treatment of patients with COPD: a summary of the ATS/ERS position paper. Eur Respir J 2004; 23: 932-946.

26 Ball P. Epidemiology and treatment of chronic bronchitis and its exacerbations. Chest 1995; 108: Suppl. 2, 43S-52S.

27 Wedzicha JA. Role of viruses in exacerbations of chronic obstructive pulmonary disease. Proc Am Thorac Soc 2004; 1: 115-120.

28 Blasi F, Damato S, Cosentini R, et al. Chlamydia pneumoniae and chronic bronchitis: association with severity and bacterial clearance following treatment. Thorax 2002; 57: 672-676. 